Article

\title{
Reactions to a Low-Fat Milk Social Media Intervention in the US: The Choose 1\% Milk Campaign
}

\author{
Robert John ${ }^{1, *}$, Karla J. Finnell ${ }^{1}$, Dave S. Kerby ${ }^{1}$, Jade Owen ${ }^{1}$ and Kendra Hansen ${ }^{2}$ \\ 1 Health Sciences Center, University of Oklahoma, Oklahoma City, OK 73126-0901, USA; \\ karla-finnell@ouhsc.edu (K.J.F.); dave.s.kerby@gmail.com (D.S.K.); jade-owen@ouhsc.edu (J.O.) \\ 2 Two Rivers Public Health Department, Suite A, Kearney, NE 68847, USA; khansen@trphd.org \\ * Correspondence: robert-john@ouhsc.edu; Tel.: +1-405-271-2017 (ext. 46755)
}

Academic Editor: Alessandra Durazzo

Received: 31 May 2017; Accepted: 23 August 2017; Published: 25 September 2017

\begin{abstract}
Background: Social media has increased in importance as a primary source of health communication but has received little academic attention. The purpose of this study was to conduct a content analysis of Facebook comments made in response to a five-week statewide social media intervention promoting use of $1 \%$ low-fat milk. Formative research identified health messages to promote, and 16 health messages consistent with the Dietary Guidelines for Americans were posted. During the intervention, 454 Facebook users posted 489 relevant comments; (2) Methods: The themes of user comments were identified using mixed-methods with qualitative identification of themes supplemented by cluster analysis; (3) Results: Six broad themes with 19 sub-themes are identified: (a) sugar, fat, and nutrients, (b) defiant, (c) watery milk, (d) personal preference, (e) evidence and logic, and (f) pure and natural; (4) The subject of milk is surprisingly controversial, a contested terrain in the mind of the consumer with a variety of competing perspectives that influence consumption. Public reactions to a social media nutrition education intervention are useful in understanding audience psychographics toward the desired behavior, require continual efforts to monitor and manage the social media campaign, but provide an opportunity to maximize the utility of real-time interactions with your audience.
\end{abstract}

Keywords: milk; social media; social marketing; Supplemental Nutrition Assistance Program (SNAP); cluster analysis; audience psychographics

\section{Introduction}

Saturated fat is an over-consumed nutrient in the American diet [1]. Since 1990, the Dietary Guidelines for Americans have been trying to get the US population to adopt 1\% low-fat milk to reduce saturated fat consumption with limited success [2], and the recommendation to consume nonfat or $1 \%$ low-fat milk has become more explicit and more pervasive in each iteration of the Dietary Guidelines [3-7].

However, the evidence is that American consumers, by and large, have not heeded the recommendation. Figure 1 displays the 40-year trend in fluid milk sales in the US [8]. From 1975 to the early 1990s, whole milk sales plummeted as $2 \%$ milk sales increased while sales of other types of milk increased slightly during the late 1980s. In 1993, 2\% milk sales exceeded whole milk sales for the first time and for the next decade whole and $2 \%$ milk sales were nearly identical. Since 2005, 2\% milk sales have consistently surpassed whole milk sales. As of 2015, 1\% low-fat and nonfat milk represents less than a third of all milk sales (30.0\%), a figure that has not changed markedly during the last decade. 


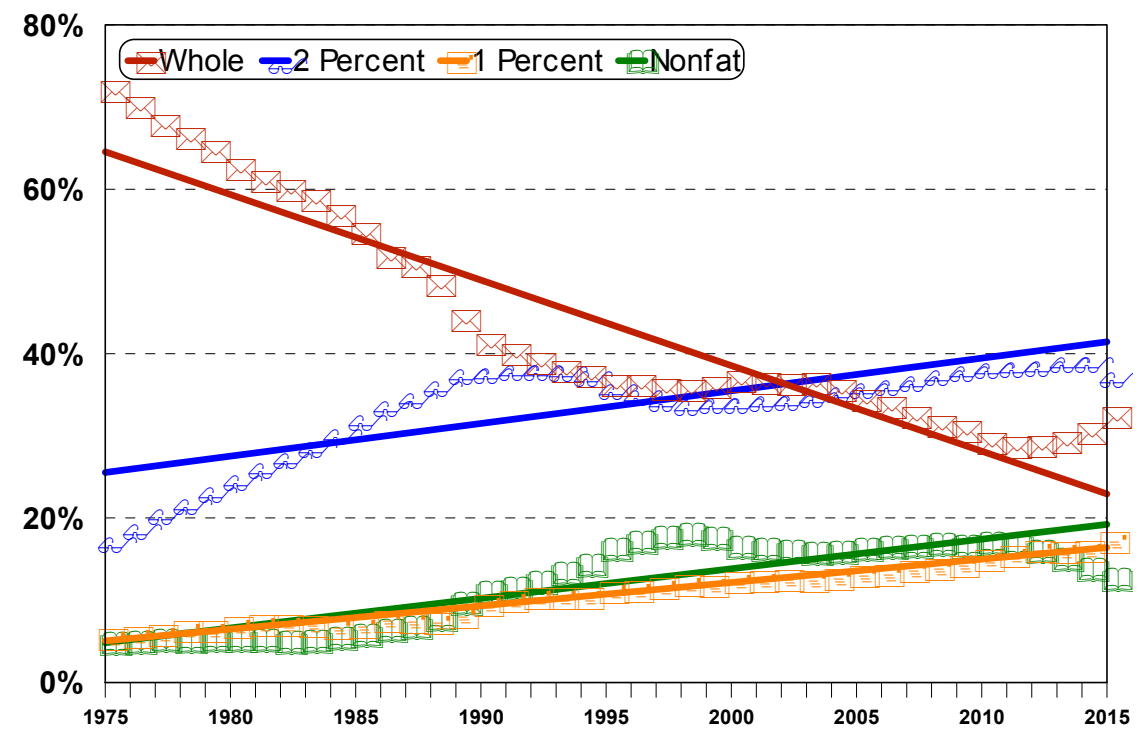

Figure 1. Actual and Trends in Fluid Milk Sales 1975-2015. Source. US Department of Agriculture; Adapted from: Fluid milk sales by product (Annual), 2016 [8].

Unfortunately, the shift toward $2 \%$ milk consumption does not achieve the aim of the Dietary Guidelines for Americans to reduce consumption of saturated fat. Replacing whole and 2\% milk with nonfat and $1 \%$ milk significantly reduces the amount of saturated fat and calories consumed at a population level [9]. Choosing 2\% milk instead of whole milk reduces saturated fat from $5 \mathrm{~g}$ per cup to $3.5 \mathrm{~g}$, a $30 \%$ reduction. In comparison, consuming $1 \%$ milk cuts the amount of saturated fat by $70 \%$ per cup.

Federal food and nutrition education programs promote adoption of the recommendations of the Dietary Guidelines for Americans [3]. Given the longstanding and consistent recommendation to consume $1 \%$ or nonfat milk, what reasons do consumers have for the slow adoption of low-fat milk? The major goal of this study is to report the spontaneous reactions of people who received one or more posts on their Facebook timeline during a five-week social media campaign on Facebook to promote consumption of $1 \%$ milk based on a content analysis of comments made by the public to the advertised posts. To our knowledge, this is the first study to report a content analysis of a social media nutrition education intervention. The reactions illustrate the competing perspectives toward the different types of milk and the utility of social media as a health promotion tool.

\section{Intervention}

The Oklahoma Nutrition Information and Education (ONIE) Project, a Supplemental Nutrition Assistance Program Education (SNAP-Ed) social marketing project, is funded by the United States Department of Agriculture through the Oklahoma Department of Human Services. As a SNAP-Ed grantee, the ONIE Project promotes good nutrition and physical activity, with a low-income priority audience $(<130 \%$ federal poverty level), especially among those who are eligible for the Supplemental Nutrition Assistance Program (SNAP), formerly known as the Food Stamp Program.

SNAP is the largest food assistance program in the US. In 2014, Oklahoma had the 15th highest rate of SNAP participation in the US with a monthly average of 608,492 SNAP beneficiaries [10], or approximately one in six Oklahomans. SNAP recipients are free to choose what type of milk they will consume or to forego milk in favor of less healthy options such as sugar-sweetened beverages. Providing the SNAP population with nutrition information about healthy options consistent with the Dietary Guidelines for Americans [3] is the purpose of the SNAP-Ed program. The large number of SNAP recipients in Oklahoma gave the ONIE Project a sizable low-income audience for the social marketing intervention. 
The purpose of this intervention, Choose 1\% Milk, was to move higher-fat milk consumers to low-fat milk use. This multi-media social marketing intervention was the second of two interventions promoting low-fat milk use conducted by ONIE. The first, implemented in 2012, featured a local athletic celebrity and was implemented in the Oklahoma City media market. Using a quasi-experimental design, both pre- and post-intervention telephone surveys and milk sales data revealed a significant and positive change in $1 \%$ milk use in the intervention media market during the course of the intervention. [11,12]. The Choose 1\% Milk intervention was implemented statewide over a five-week period. Social media, particularly Facebook, was a primary channel. Evaluation of milk sales data collected from 105 supermarkets located throughout the state of Oklahoma revealed that $1 \%$ milk sales increased significantly during the Choose 1\% Milk intervention. The market share of $1 \%$ milk sold increased from $7.1 \%$ the week prior to the intervention to $10.1 \%$ immediately after it ended, a $42.9 \%$ relative increase. The overall quantity of milk sold did not significantly increase, suggesting that the increase in $1 \%$ milk sales was a result of high-fat milk users changing to $1 \%$ milk. In addition, nonfat milk sales did not significantly change, ruling out that nonfat milk users contributed to the increase in $1 \%$ milk sales.

\section{Materials and Methods}

\subsection{Materials}

The campaign logo was the image of an arm reaching for a gallon of $1 \%$ milk, with the word "Choose" prominently displayed. The tag line was "Choose 1\% Milk", and the secondary tag line was "A Healthy Family Choice" (see Figure 2). The emphasis on choice came from studies of political communication by Luntz [13], and our own formative research that showed a positive reaction to messages conferring autonomy [14]. Similar to our previous intervention, the campaigns' key messages sought to dispel the most common myths held by SNAP recipients about $1 \%$ milk [14] including the differences in the fat content between $2 \%$ and $1 \%$ milk, that $1 \%$ milk has the same vitamins and minerals as whole milk, $1 \%$ milk is not watered-down, and $1 \%$ milk is recommended for children age two and older. All advertisements posted on social media relied heavily on infographic images. These images were simple but clever, and key messages communicated nutrition information with only a few words.

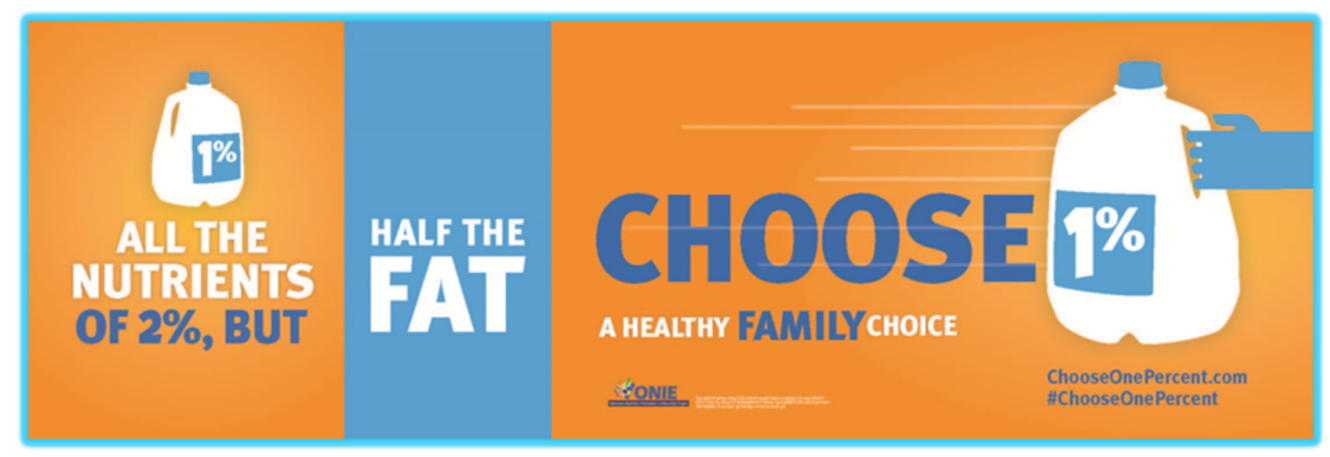

Figure 2. Choose 1\% Milk Social Media Infographic.

\subsection{Participants}

ONIE collected the data from Facebook users who chose to respond to the health promotion messages about $1 \%$ milk during the Choose 1\% Milk intervention by writing a comment about the post. There were no recruitment efforts or solicitations to obtain comments beyond the appearance of the paid advertisement (post) on each individual's timeline. In addition to residing in Oklahoma and adults age 18 and over, the characteristics of the individuals who would receive the post were specified when the advertisement was published on Facebook. Table 1 lists the priority audience profile for each 
post. Each post was targeted to the Facebook users who fit one or more of the characteristics specified. No personal information was gathered, so how many were SNAP participants is not known but there is no evidence to suggest that the SNAP population is underrepresented on Facebook.

Table 1. Facebook Advertisements and Social Media Participation (2014).

\begin{tabular}{|c|c|c|c|c|c|c|c|c|}
\hline Post \# & $\begin{array}{l}\text { Date } \\
\text { Posted }\end{array}$ & Advertisement & $\begin{array}{l}\text { People } \\
\text { Reached }\end{array}$ & $\begin{array}{l}\text { Post- } \\
\text { Clicks }\end{array}$ & Likes & Shares & $\begin{array}{l}\text { Comments } \\
\text { Analyzed }\end{array}$ & $\begin{array}{c}\text { Cost Per } \\
\text { Engagement (Like, } \\
\text { Comment, Share \& } \\
\text { Post-Click) }\end{array}$ \\
\hline & $9 / 16$ & Campaign launched. & & & & & & \\
\hline 1 & $9 / 16$ & $\begin{array}{l}\text { Fact: } 1 \% \text { milk has all the nutrients of } \\
2 \% \text {, but with half the fat. } \\
\text { Priority Audience: Motherhood, } \\
\text { fatherhood, parenting, parent, } \\
\text { pregnancy, family and relationships }\end{array}$ & 110,592 & 1042 & 222 & 20 & 30 & $\$ 0.44$ \\
\hline 2 & $9 / 18$ & $\begin{array}{l}\text { Add a little sunshine to your diet } \\
\text { with } 1 \% \text { low-fat milk. It has all the } \\
\text { Vitamin D of } 2 \% \text { milk. } \\
\text { Priority Audience: Fans and friends } \\
\text { of fans }\end{array}$ & 52,608 & 157 & 72 & 4 & 5 & $\$ 1.24$ \\
\hline 3 & $9 / 19$ & $\begin{array}{l}\text { Don't be a bonehead! Next time you } \\
\text { buy milk, choose } 1 \% \text { ! } \\
\text { Priority Audience: Motherhood, } \\
\text { fatherhood, parenting, pregnancy, } \\
\text { family, and relationships }\end{array}$ & 73,888 & 2103 & 1387 & 69 & 64 & $\$ 0.16$ \\
\hline 4 & $9 / 21$ & $\begin{array}{l}\text { Did you know that } 1 \% \text { milk has all } \\
\text { the vitamins and minerals as } 2 \% \\
\text { milk, but with half the fat? } \\
\text { http:// chooseonepercent.com } \\
\text { Priority Audience: Motherhood, } \\
\text { fatherhood, parenting, pregnancy, } \\
\text { family, and relationships }\end{array}$ & 99,424 & 745 & 655 & 29 & 38 & $\$ 0.40$ \\
\hline 5 & $9 / 24$ & $\begin{array}{l}\text { Build strong muscles and bones with } \\
1 \% \text { low-fat milk. It's the ultimate } \\
\text { protein drink! } \\
\text { http:/ / chooseonepercent.com } \\
\text { Priority Audience: Motherhood, } \\
\text { fatherhood, parenting, pregnancy, } \\
\text { family, and relationships }\end{array}$ & 99,488 & 513 & 500 & 19 & 25 & $\$ 0.70$ \\
\hline 6 & $9 / 26$ & $\begin{array}{l}\text { We all know } 1 \% \text { milk has less fat, but } \\
\text { does it have less vitamin D? No! } \\
\text { Priority Audience: Motherhood, } \\
\text { fatherhood, parenting, pregnancy, } \\
\text { family, and relationships }\end{array}$ & 110,208 & 974 & 1081 & 62 & 41 & $\$ 0.34$ \\
\hline 7 & $9 / 26$ & $\begin{array}{l}\text { Fact: } 1 \% \text { milk is not watered down! } \\
\text { It has all the calcium of } 2 \% \text {, but less } \\
\text { saturated fat. } \\
\text { http:// chooseonepercent.com } \\
\text { Priority Audience: Fans and friends } \\
\text { of fans }\end{array}$ & 51,344 & 366 & 150 & 11 & 9 & $\$ 1.15$ \\
\hline 8 & $9 / 30$ & $\begin{array}{l}\text { Just the facts: } 1 \% \text { milk has all the } \\
\text { protein, vitamin D and calcium of } \\
2 \% \text {, but with half the fat! Make the } \\
\text { choice for a healthier you-and a } \\
\text { healthier family. } \\
\text { http:// chooseonepercent.com } \\
\text { Priority Audience: Low-income, } \\
\text { parenting, family, and fitness }\end{array}$ & 28,864 & 480 & 124 & 8 & 21 & $\$ 0.82$ \\
\hline 9 & $10 / 7$ & $\begin{array}{l}\text { FACT: } 2 \% \text { milk contains double the } \\
\text { amount of fat found in } 1 \% \text {. } \\
\text { Priority Audience: } 18-65+\end{array}$ & 122,816 & 610 & 155 & 19 & 53 & $\$ 0.67$ \\
\hline 10 & $10 / 7$ & $\begin{array}{l}\text { Q: Which has more sugar, } 1 \% \text { milk or } \\
2 \% \text { ? A: Trick question! They're the } \\
\text { SAME. } \\
\text { Priority Audience: Parenting }\end{array}$ & 120,704 & 674 & 333 & 11 & 23 & $\$ 0.95$ \\
\hline 11 & $10 / 8$ & $\begin{array}{l}\text { Lots of people believe the fat in milk } \\
\text { is healthy, but the majority of studies } \\
\text { show that } 1 \% \text { is a better choice. } \\
\text { Priority Audience: Fans and friends } \\
\text { of fans }\end{array}$ & 68,640 & 699 & 176 & 14 & 44 & $\$ 0.99$ \\
\hline
\end{tabular}


Table 1. Cont.

\begin{tabular}{|c|c|c|c|c|c|c|c|c|}
\hline Post \# & $\begin{array}{l}\text { Date } \\
\text { Posted }\end{array}$ & Advertisement & $\begin{array}{c}\text { People } \\
\text { Reached }\end{array}$ & $\begin{array}{l}\text { Post- } \\
\text { Clicks }\end{array}$ & Likes & Shares & $\begin{array}{l}\text { Comments } \\
\text { Analyzed }\end{array}$ & $\begin{array}{c}\text { Cost Per } \\
\text { Engagement (Like, } \\
\text { Comment, Share \& } \\
\text { Post-Click) }\end{array}$ \\
\hline 12 & $10 / 10$ & $\begin{array}{l}\text { FACT: Once children reach } 2 \text { years of } \\
\text { age, they don't need the fat in } 2 \% \\
\text { and whole milk to grow. } 1 \% \text { is the } \\
\text { healthy choice! } \\
\text { Priority Audience: Mother, } \\
\text { fatherhood, and parenting }\end{array}$ & 147,904 & 1053 & 750 & 92 & 103 & $\$ 0.55$ \\
\hline 13 & $10 / 13$ & $\begin{array}{l}\text { On average, it takes } 2 \text { weeks to } \\
\text { adjust to the taste of } 1 \% \text { milk and } \\
\text { you still get the nine essential } \\
\text { nutrients of milk! } \\
\text { Priority Audience: Low-income }\end{array}$ & 79,648 & 1077 & 220 & 23 & 51 & $\$ 0.81$ \\
\hline 14 & $10 / 14$ & $\begin{array}{l}\text { Get your fats straight! } \\
\text { Priority Audience: } 18-65+\end{array}$ & 161,792 & 829 & 312 & 12 & 47 & $\$ 0.87$ \\
\hline 15 & $10 / 14$ & $\begin{array}{l}\text { Kick the excessive sugars and } \\
\text { additives in sports drinks. } 1 \% \text { milk is } \\
\text { packed with vitamins and nutrients } \\
\text { your body needs! } \\
\text { Priority Audience: Parenting }\end{array}$ & 102,112 & 402 & 491 & 25 & 18 & $\$ 1.20$ \\
\hline \multirow[t]{3}{*}{16} & $10 / 17$ & $\begin{array}{l}\text { Children need milk. The American } \\
\text { Academy of Pediatrics recommends } \\
1 \% \text { milk after the child's second } \\
\text { birthday } \\
\text { Priority Audience: Motherhood, } \\
\text { fatherhood, parenting, pregnancy, } \\
\text { family, and relationships }\end{array}$ & 105,920 & 351 & 517 & 34 & 20 & $\$ 0.57$ \\
\hline & $10 / 17$ & Campaign ended & & & & & & \\
\hline & & Totals & $1,535,952$ & 12,075 & 7145 & 452 & 592 & $\$ 0.74$ \\
\hline
\end{tabular}

\subsection{Statistical Analysis}

The themes of Facebook comments were identified qualitatively by four raters, each reading the comments independently. Each rater read the comments repeatedly to become familiar with them and to identify themes. The themes were not mutually exclusive, as raters may have assigned one comment to more than one theme.

In addition, the qualitative approach was supplemented by the quantitative method of cluster analysis. The need for cluster analysis comes from the fact that the social media material lacks the context of a group conversation, such as occurs with a focus group. Rather, social media content is briefer and less contextual. Cluster analysis has been in regular use in the social sciences since the 1960s and new applications continue to be reported [15-17]. We introduce cluster analysis as a quantitative method to classify the content of the themes identified by the raters for each comment. For this study, the analysis was a cluster of cases. Each case was a theme identified by an individual rater and groups of similar themes were identified by cluster analysis [18-20].

To provide converging evidence, two measures of similarity were used. The first measure of similarity was the Dice coefficient. It can range from 0 to 1 , with a higher score meaning more similarity [21]. The second measure of similarity was Yule's $Q$, a correlation-like measure that ranges from -1 to +1 , with a score of zero meaning no relationship [22]. A key property of Yule's $Q$ is that when one rater's theme consists of a subset of comments from another rater's theme, then Yule's $Q$ is equal to one, a relationship described as complete [23]. When Yule's $Q$ is higher than the Dice coefficient, this suggests that one theme may be more general than another, so inspection of the items is warranted to explore this possibility.

For both the Dice coefficient and Yule's Q, themes were combined by average linkage between-groups. The final step in the analysis was again qualitative. The clusters of themes were examined qualitatively to verify similarities, and the raters reviewed the comments one last time to detect any themes that had not previously been identified. 


\section{Results}

As seen in Table 1, during the Choose 1\% Milk campaign, ONIE posted 16 different advertisements on Facebook. These advertisements were seen by 1.54 million people (reach). Reach is tracked by individual advertisment post not by the entire campaign, so this figure includes duplicated viewers who saw more than one of the posts. On average, each advertisement reached approximately 96,000 people (unique count). The total population in Oklahoma in 2014 was 3,878,051 people, meaning each advertisement was seen by $2.5 \%$ of the population [24]. A total of 8374 Facebook users engaged with the 16 posts by responding with a like, a share, or a comment. The 16 posts resulted in more than 12,000 clicks to read more about the topic, more than 7000 likes, and 452 shares. By definition, likes are positive endorsements of the message. A share indicates that the Facebook user shared the post on their timeline, which extends its reach to their family and friends. Another level of engagement is to write a comment, which may support or oppose the health message.

During the campaign, 454 Facebook users commented 592 times. Most commented only once $(81.7 \%)$ or twice $(12.8 \%)$, but 25 users $(5.5 \%)$ commented three or more times. Of the 592 comments analyzed 103 (17.4\%) were off topic, such as a thread in which users discuss diabetes with no reference to milk. Thus, there were 489 comments that related in some way to the health message about $1 \%$ milk.

The four raters individually read through these 489 comments and identified themes. The four raters identified 15, 18, 20, and 24 themes respectively for a total of 77 themes, some of which used very similar or the same words to describe the theme. These themes were subjected to cluster analysis so that themes sharing the same comments were grouped into similar clusters. Examination of the dendrogram suggested that a good solution was six broad thematic groups. A total of 19 more specific sub-themes emerged from within the broad thematic groups as summarized below in Table 2. In the final qualitative step, raters reviewed the comments and themes, and no additional themes were identified. Discussion of the themes is ordered by the number of comments in each group, presuming that frequency is indicative of more common or more intensely held beliefs.

Table 2. Themes and Sub-themes of the Content Analysis.

\begin{tabular}{|c|c|}
\hline Thematic Group & Sub-Theme Comment [Facebook Post \# in Table 1] \\
\hline \multirow{4}{*}{$\begin{array}{l}\text { 1. Sugar, Fat, and Nutrients } \\
(n=118)\end{array}$} & $\begin{array}{l}\text { Fat and Sugar }(n=37) \\
\text { What they take out of whole milk they replace with sugar/sweetener. [\#5] } \\
\text { The lower the fat content, the higher the sugar content. [\#1] } \\
\text { And full of sugar! [\#7] } \\
\text { Flavored sugar filled milk contributes way more to childhood obesity. [\#12] } \\
\text { This is so wrong. Stop selling garbage information to young parents and killing our babies with } \\
\text { sugar...[\#12] } \\
\text { Sugar water [\#3] }\end{array}$ \\
\hline & $\begin{array}{l}\text { Nutrients }(n=35) \\
\text { I could be wrong, but aren't all nutrients super-heated out then added back in? Hydrogenated [sic] means } \\
\text { super-heated. [\#13] } \\
1 \% \text { has more vitamins because it has more milk. [\#9] } \\
\text { With that logic lots of things are "packed" with nutrients, but the amounts are very little. [\#13] } \\
\text { One percent milk has no vitamins to make bones grow strong and help the teeth also.[\#12] }\end{array}$ \\
\hline & $\begin{array}{l}\text { Healthy Fat }(n=31) \\
\text { Actually low fat has been shown to be ineffective at weight loss. [\#7] } \\
\text { Fat is required to digest nutrients found in milk. [\#14] } \\
\text { Did you know that the fat in whole milk is good for you? [\#4] } \\
\text { Yup fat and cholesterol are good for you. [\#1] } \\
\text { Wow another lie this milk... has no vitamins at all bc it's in the fat content...take a nutrition class. [\#2] }\end{array}$ \\
\hline & $\begin{array}{l}\text { Fat is Good for Children }(n=16) \\
\text { There are fats in whole milk that help children's brain development. [\#14] } \\
\text { For adults it's better, but for children it's not. [\#6] } \\
\text { Children's brains NEED good fats to develop. [\#12] }\end{array}$ \\
\hline
\end{tabular}


Table 2. Cont.

\begin{tabular}{|c|c|}
\hline Thematic Group & Sub-Theme Comment [Facebook Post \# in Table 1] \\
\hline \multirow{3}{*}{ 2. Defiant $(n=110)$} & $\begin{array}{l}\text { Rejection }(n=75) \\
\text { BS, } 1 \% \text { milk is worthless. [\#4] } \\
\text { No one really knows wtf is good or bad for you now-a-days. [\#3] } \\
\text { Don't care. Not drinking } 1 \% \text {. [\#10] }\end{array}$ \\
\hline & $\begin{array}{l}\text { Sarcasm }(n=30) \\
\text { Well duh! [\#9] } \\
\text { How much time and money were wasted to come to this incredible conclusion? [\#9] }\end{array}$ \\
\hline & $\begin{array}{l}\text { Tyranny }(n=8) \\
\text { How about we let the parents do the parenting......1\% is yuk! [\#12] } \\
\text { Government at work in our homes now!!!!! [\#4] } \\
\text { Stupid government telling people how to eat and everyone's falling for it. SMH. [\#12] }\end{array}$ \\
\hline \multirow{3}{*}{$\begin{array}{l}\text { 3. Watery Milk } \\
(n=98)\end{array}$} & $\begin{array}{l}\text { Sensory Experience }(n=77) \\
\text { Might as well drink water. No taste. [\#6] } \\
\text { It's blue tinged. [\#12] } \\
\text { When I drink milk, I want to taste milk, not water. [\#9] } \\
\text { My words exactly whole milk...1\% is blue water!!! [\#3] }\end{array}$ \\
\hline & $\begin{array}{l}\text { Watered Down }(n=31) \\
\text { We come from a dairy farm and we don't want our milk watered down. [\#3] } \\
100 \% \text { milk builds strong bones. Not watered down fake 1\%! [\#3] } \\
\text { It is mostly water. [\#4] } \\
\text { It's just water with a splash of milk in it duh [\#9] }\end{array}$ \\
\hline & $\begin{array}{l}\text { Cost }(n=8) \\
\text { They make more money off } 1 \% \text { milk! (Less milk and more water!) [\#3] } \\
\text { It's about money. [\#10] } \\
\text { You are paying for mostly water. [\#13] } \\
\text { Read the labels folks. They must own stock in a water company [\#16] }\end{array}$ \\
\hline \multirow{3}{*}{$\begin{array}{l}\text { 4. Personal Preference } \\
(n=93)\end{array}$} & $\begin{array}{l}\text { Likes High-Fat Milk }(n=50) \\
\text { Whole milk all the way. [\#3] } \\
\text { Whole milk is my favorite. [\#5] } \\
2 \% \text { is my fav. [\#6] }\end{array}$ \\
\hline & $\begin{array}{l}\text { Likes Low-Fat Milk }(n=30) \\
\text { I love skim milk! [\#1] } \\
1 \% \text { is our choice. [\#5] } \\
\text { We have been drinking } 1 \% \text { for years, and love it. [\#9] }\end{array}$ \\
\hline & $\begin{array}{l}\text { Raw Milk }(n=23) \\
\text { Straight from the cow or nothing. [\#6] } \\
\text { Not just whole milk but whole RAW milk is the healthiest of all. [\#4] } \\
\text { I want it fresh from the cow. [\#8] }\end{array}$ \\
\hline \multirow{3}{*}{$\begin{array}{l}\text { 5. Evidence and Logic } \\
(n=79)\end{array}$} & $\begin{array}{l}\text { Scientific Evidence }(n=38) \\
\text { False advertising. There is absolutely no scientific evidence that people who drink cow's milk have stronger } \\
\text { bones. [\#3] } \\
\text { Studies have come out to show that's not true. Whole milk is best. [\#12] } \\
\text { My son's Dr says that } 2 \% \text { is best. [\#12\} } \\
\text { I challenge the person who came up with this crazy idea to prove it.[\#12] }\end{array}$ \\
\hline & $\begin{array}{l}\text { Anecdotal Evidence }(n=32) \\
\text { Whole milk is the best. Pioneers didn't have } 1 \% \text { and they survived just fine. [\#3] } \\
\text { I find it funny that our grandparents and great grandparents drank whole milk if it wasn't straight from a } \\
\text { cow and lived to be a ripe old age. [\#3] } \\
\text { I've been drinking whole milk my entire life and have never been over weight, even after two kids. [\#13] }\end{array}$ \\
\hline & $\begin{array}{l}\text { Exercise }(n=14) \\
\text { Walk a little more and enjoy the } 2 \text { percent. [\#9] } \\
\text { Fat free or low fat isn't the answer. Portion control and exercise. [\#14] } \\
\text { Wow the Time we talk about this you could have walked outside and said high to the neighbors, and burnt } \\
\text { more fat than a glass of milk would provide. [\#12] }\end{array}$ \\
\hline \multirow{3}{*}{ 6. Pure and Natural $(n=64)$} & $\begin{array}{l}\text { Nature }(n=33) \\
\text { There's nothing wrong with the milk God made. [\#12] } \\
\text { The vitamins and minerals are added to } 1 \% \text { they aren't natural. [\#9] } \\
\text { Milk is from nature. Store milk is from chemistry. [\#6] }\end{array}$ \\
\hline & $\begin{array}{l}\text { Milk Alternatives ( } n=21) \\
\text { I will just drink my almond milk! [\#14] } \\
\text { Cow's milk is nasty. I much prefer plant milks. [\#3] } \\
\text { Use unsweetened soy milk and let the calves drink the milk they should be getting. [\#13] }\end{array}$ \\
\hline & $\begin{array}{l}\text { Contamination }(n=19) \\
\text { May have Vitamin D but it also has growth hormones that are not good for us!! [\#2] } \\
\text { Milk has pus from cows, hormones and antibiotics. [\#13] } \\
\text { Investigate the chemicals used to remove the fat from milk!! [\#6] }\end{array}$ \\
\hline
\end{tabular}

Note: The $n$ for each major thematic group is the number of non-duplicate comments in the group, which may be less than the sum of the $n$ comments for the sub-themes in that group. 


\subsection{Thematic Group 1: Sugar, Fat, and Nutrients}

Sugar, fat, and nutrients had the most comments $(n=118)$ with four sub-themes. The comments in this thematic group, whether positive or negative, refer to beliefs about the nutrients in different types of milk. Comments in the sub-theme of Fat and Sugar $(n=37)$ refer to sugar or fat or both. Some comments were neutral, but many contained arguments against drinking $1 \%$ milk. Some Facebook users mistakenly believed that sugar was added to low-fat milk. Others considered $1 \%$ milk a trade-off, such that less fat means more sugar.

Comments in the sub-theme of Nutrients $(n=35)$ refer to the general topic of nutrition, such as the mention of calcium or protein, or of individual differences in nutritional needs. Generally, these comments claimed that the vitamins and minerals in low-fat milk are lower in amount or quality. A second erroneous assumption was that all the vitamins in milk are fat soluble, so drinkers of low-fat milk do not absorb the vitamins in milk.

In the sub-theme of We Need the Fat, there are 31 comments. These comments argue that whole milk is better, because dietary fat is healthy or at least not harmful to health. Also, like the comments in the Nutrients sub-theme, there is the belief that low-fat milk is less nutritious. However, the comments in this sub-theme imply that the nutrients in milk are in the fat, and that removing the fat also removes the nutrients.

Finally, in the sub-theme of Fat is Good for Children, there are 16 comments. These comments refer specifically to the nutritional needs of children. These comments support giving whole milk to children, and many express the belief that fat is important for children age two and older to develop; in fact, about one out of three of these comments specifically referred to brain development.

\subsection{Thematic Group 2: Defiant}

Harsh or negative comments rejecting the health promotion message cluster into the second largest thematic group ( $n=110)$ with three sub-themes. The 75 comments in the sub-theme Rejection disputed the message. Examples were "why bother", "no way", "bull" and "yuck." Some comments were hostile or contained profanity, and others questioned the validity of the key messages.

The sub-theme labeled Sarcasm consisted of 30 comments ridiculing the post. Notably, half of these comments emerged in response to one advertisement (Table 1,\#9) that illustrated the difference in the fat content between $2 \%$ and $1 \%$ milk with the key message, "FACT: $2 \%$ milk contains double the amount of fat found in 1\%". Responses included "Well duh!" and "How much time and money were wasted to come to this incredible conclusion?" This particular ad received few likes, as well.

The third sub-theme has only eight comments, and it is labeled Tyranny. These comments often explicitly say that the health message was wrong. For example, “This is all hog wash! Give those kids REAL milk and cut the fat somewhere else." They also refer to the message as an example of tyrannical political action and the government telling people what to do.

\subsection{Thematic Group 3: Watery Milk}

The formative research had revealed a pervasive belief that $1 \%$ milk was watered-down whole milk, and comments in this theme affirm that this is an important belief influencing the type of milk consumed. Each subtheme captures a unique aspect of this belief.

The Sensory Experience sub-theme made invidious comparisons of $1 \%$ to higher-fat milk, stating that whole milk is an appealing white with a pleasing thick texture and rich taste, but that $1 \%$ milk has a bluish tint with a watery texture and no flavor $(n=31)$. In contrast, comments in the sub-theme named Watered Down $(n=33)$ explicitly spoke of added water or called $1 \%$ milk white water or colored water. Cost, the last sub-theme in this group, contained eight comments. These comments express the view that milk producers and marketers added water to milk to make more money. 


\subsection{Thematic Group 4: Personal Preference}

The comments clustered together in this theme focused on what type of milk the commenter preferred and not the attributes of the type of milk $(n=93)$. Slightly more than half of these comments expressed a personal liking for $2 \%$ or whole milk through attitude or behavior. The 30 comments in the sub-theme Likes Low-Fat Milk are similar, but the personal preference is for low-fat milk. Finally, in a third sub-theme named Raw Milk, the Facebook user stated the desire to have raw milk, or to have milk straight from the cow $(n=33)$.

\subsection{Thematic Group 5: Evidence}

Comments of the Facebook users in this theme $(n=79)$ offered scientific, antidotal, or wellestablished facts to justify their beliefs. Those in the sub-theme we labeled Scientific Evidence $(n=38)$ justified their position by referencing scientific evidence. The source may have been rather vague, such as a reference to research studies in general, or the source may have been fairly specific, as in a well-known television personality who offers expert advice, or their family physician. Some Facebook users cited a media outlet as the source of evidence or provided links to research findings from the media outlet itself.

In the sub-theme named Anecdotal Evidence $(n=32)$ comments cited a personal experience or anecdotal evidence, not scientific research. These Facebook users usually referred to themselves or family members who have used whole milk for years and are healthy. Some people referenced ancestors' consumption of milk before the west was settled, presuming these pioneers had been healthy.

The sub-theme named Exercise has 14 comments. The nature of the evidence in these comments is the fact that weight can be lost by increasing physical activity. These comments rejected the message of the health benefits of low-fat milk by asserting that the problem can be resolved with exercise.

\subsection{Thematic Group 6: Pure and Natural}

The last thematic group contained 64 comments, which was the smallest number of comments ( $13.1 \%$ of the total). These comments rejected the use of $1 \%$ milk on the grounds that it is not pure or natural.

Comments grouped in the sub-theme Nature $(n=33)$ reflected a belief that adult milk consumption was unnatural, noting that milk is for babies and not for adults. Others rejected milk sold in stores on the grounds it was an unnatural processed food item, preferring raw milk. Similarly, but slightly different, others rejected low-fat milk claiming that it is processed but whole milk is natural.

There were 21 comments in the sub-theme Milk Alternatives. These statements rejected the use of dairy milk, sometimes on the grounds that drinking the milk of another species is unnatural, and recommend the use of milk from plants sources, such as almond or soymilk.

The third sub-theme in this group is labeled Contamination. The 19 comments in this sub-theme refer to the belief that milk products are contaminated. In some comments, the nature of the contaminant vaguely referenced chemicals or additives. Others were more specific, as in a reference to hormones, antibiotics, pus, or pesticides. A number of Facebook users linked their comments to blogs that assert that dairy contains a host of contaminates and is not safe for human consumption as evidence supporting their comments. These commenters were strongly opposed to the use of dairy milk.

\section{Discussion}

Facebook is a nascent community of sorts and some users want to actively participate or interact with others. A well-executed social media campaign captures the attention of the audience, who then engage with both negative and positive comments. Yet, public health campaigns have been slow to make use of the interactive nature of social media [25]. This study examined the content of spontaneous 
Facebook comments made in response to a successful social marketing intervention with statewide exposure on social media, the Choose 1\% Milk campaign.

Six broad themes illustrate the types of comments that emerged. These included: (1) Sugar, Fat, and Nutrients, the interest in the nutritional content of milk; (2) Defiant, the expression of defiant and negative attitudes toward the health message; (3) Watery Milk, the concern that low-fat milk has added water or has the sensory qualities of water; (4) Personal Preference, a statement endorsing what is familiar and liked in a milk product; (5) Evidence and Logic, the dismissal of the health benefits of $1 \%$ milk by appeal to contrary anecdotes or to the lack of research support for the touted benefits; and (6) Pure and Natural, the idea that whole milk is pure and natural, but low-fat milk is impure, adulterated, or unnatural.

The thematic group Watery Milk contained the most common sub-theme Sensory Experience, with 77 comments about flavor and texture. This theme was expected, because concerns about the sensory difference between whole milk and low-fat milk appeared in our formative research, and because sensory preferences are a recognized motive for food choice [26]. In fact, taste preference is a leading reason to choose food items [26,27].

There was also the theme Watered Down, whose comments expressed the belief that low-fat milk has added water, implying inferior nutrition. Again, we expected to encounter this belief, as it appeared in the formative research [12,14], and it has appeared in previous research on low-fat milk [28]. These comments affirm the relevance of key messages and the need to repeat messages challenging strongly held beliefs to create a shift in attitudes [29]. Moreover, the interactive nature of social media is a desirable feature that allowed the campaign team to reply with comments to correct this mistaken idea of added water. A possible strategy for future campaigns is to monitor the frequency of such comments over time to see if they diminish.

The benefit of using the interactive nature of social media is illustrated with the thematic group Sugar, Fat, and Nutrients. One sub-theme in this group was Fat and Sugar, the belief that lower fat in milk means more sugar. This belief did not appear in formative research but emerged as a barrier to the adoption of low-fat milk for this audience segment. Because Facebook is not static, new advertising content can be developed quickly and inexpensively. ONIE took advantage of this feature and posted: "Q: Which has more sugar, $1 \%$ milk or $2 \%$ ? A: Trick question! They're the SAME." This advertisement reached 120,704 Facebook users and received a high level of engagement.

Effective use of social media's ability to react quickly and interact directly with the audience is also illustrated with the thematic group Pure and Natural. Some Facebook users argued that milk from soy or almonds was more natural, using the Choose 1\% Milk campaign to promote their personal philosophical nutrition beliefs. These non-dairy milk users were not the priority audience for Choose $1 \%$ Milk campaign. Yet, comments devaluing dairy milk had the potential to adversely affect milk consumption, an unintended and undesirable outcome. The ONIE team politely responded to some of these comments to reassure milk users that dairy milk is safe. The lesson for public health practitioners is that in an interactive campaign on any topic, one may be called on to address related competing behaviors and other potential unintended consequences.

Comments in the thematic group Personal Preference referred to milk that was familiar and typically consumed. This theme is similar to the familiarity motive from the Food Choice Questionnaire [26], in which people said they chose a food because it "is what I usually eat" or "is like the food I ate when I was a child." ONIE formative research also identified this theme [12,14]. As its strategy to reduce familiarity as a barrier to low-fat milk use, when online comments promoted whole or $2 \%$ milk, the ONIE team offered no response; but when comments supported low-fat milk, ONIE "liked" the comments and crafted responses affirming the behavior. In this way, the interactive nature of social media was used to further promote a positive health message.

Another thematic group in the Facebook comments was called Evidence and Logic. This audience segment claims to select food to promote health. Regardless of the type of milk consumed, milk users often identified health benefits as a motivating factor for the type of milk used [12,14], a factor identified 
as influencing food choices generally as well [26]. This audience segment wants current scientific evidence of the health benefit and resolution of conflicting nutritional advice. Previous research has found a desire by mothers in a nutrition program to be provided with information based on trustworthy research, including external links to more information [30], and the Food Hero program recommends providing research-based information [31]. To support these Facebook users need for more information, ONIE project staff responded with research-based information and links to more information. A strategy for future campaigns would be to compile a summary of credible research findings and share the summary in replies to those who seem to want evidence to support particular claims. Also, comments directed to ONIE asked who we were and what our motives were, so we were transparent about our funding source and mission.

At the same time, not all of the comments indicated openness to scientific evidence. The thematic group Evidence and Logic included the theme of Anecdotal Evidence. These comments put little credence in scientific research evidence, and instead appealed to anecdotes. The study of the spread of misinformation has been described as network sociology, and "it may be as influential as the information content and scientific validity of a particular health topic discussed using social media" ([32], p. 517). It may be useful for future research to examine how an appeal to anecdotes affects the spread of public health messages.

The last thematic group was named Defiant. These comments expressed negative attitudes using sarcasm, hostile remarks, profanity, and cynical attitudes toward government, many of which were not appropriate for a family-oriented Facebook page. Comments like these did not arise during the formative research from focus groups or from a telephone survey, so the negative comments appear to arise from the nature of social media. One challenge for social media campaigns is how to address such negative comments. One study of Twitter examined tweets on the public health topic of HPV vaccines, with the results indicating that users exposed to negative tweets were more likely to make a negative tweet [33]. To manage the social media, ONIE staff monitored comments throughout the day and evening. Profanity was deleted, and gratuitous insults were hidden from view of anyone except ONIE staff and the Facebook user making the comment. Comments that were merely negative about the health message, with no profanity or degrading language, were ignored. It can be noted that many of these comments were directed at one post (Table 1, \#9). Perhaps this message was interpreted as condescending, obvious by definition, or too simple to be interesting or informative. So there may be a lesson to be learned for social media campaigns on any health topic: messages must be simple and direct but without appearing condescending.

We found the cluster analytic method introduced here to be a useful tool to study social media content. Unlike material from a focus group in which statements are part of a dialogue and comments are related to what comes before as well as after the comment (i.e., have a meaning-laden context), the Facebook comments were brief statements, usually one sentence, and sometimes merely a phrase. Material from other social media platforms is similarly stand-alone content, such as tweets, or pictures from Instagram. Given the lack of context and narrative structure to the material and the depersonalized context, cluster analysis could be helpful in identifying similar themes. The use of and consensus among four raters also added evidence for the reliability of the results.

To maximize the use of the interactive nature of social media, we have several suggestions: be transparent about funding sources and the purpose of the campaign; repeat key messages in advertising posts countering or challenging strongly held beliefs and monitor comments to identify whether the frequency of these type of comments diminish; keep comments brief and simple without appearing condescending; develop new posts to respond quickly to themes that emerge from comments; dedicate staff to monitor comments, delete or hide those with profanity or personal attacks, engage with Facebook users who comment, and assess the influence of comments on the promoted behavior. Another lesson learned is to promote engagement by directly asking the audience to participate such as by asking a question, which allows viewers to participate immediately and quickly. 
Social media is quickly becoming a dominant source of all communication including health communication, transforming with whom and how people interact, obtain information and voice their opinions. It is more engaging than other media channels for health promotion interventions because it supports dialogue, a key element in developing a critical perspective on a topic [34]. In addition, it is a sure pathway into the social networks of a person's friends and family. Given the rapid extension of social media, public health needs to embrace this medium and do everything to add to our understanding of how to make it work to improve population health.

The adoption of $1 \%$ milk has been slow in the US. Americans need a compelling reason to adopt $1 \%$ low-fat milk. If adopting $1 \%$ low-fat milk provides health benefits sufficient to warrant repeated recommendation in the last six Dietary Guidelines for Americans, what can be done to improve adoption by the public? The comments received to the 16 posts, all of which were consistent with the recommendations made in the Dietary Guidelines for Americans since 1990, provide additional insight on the question. The subject of milk is a contested terrain in the mind of the consumer with a variety of competing perspectives grounded in accurate or mistaken nutrition knowledge about the nutritional content of the different types of milk, rational and non-rational thought (scientific evidence vs. personal preference, feelings about family or personal experience), competing scientific findings (good fat, bad fat), and political philosophy and beliefs about nature, government tyranny and corporate greed. Although some of the reasons to reject any change in milk consumption could be anticipated (such as lack of or mistaken nutrition knowledge or preference for a non-animal diet), milk consumption is a controversial issue and it is easy for people to find an opinion about milk that makes sense to them. If adopting $1 \%$ milk has all of the alleged or anticipated benefits, making a more explicit recommendation every five years will not change behavior very quickly as evidence from the last 27 years reveals. Instead, a concerted and consistent effort to acknowledge all of these competing claims and address them to the extent possible is the only apparent way to achieve the recommendation to make consumption of $1 \%$ or nonfat milk the social norm.

Acknowledgments: Partial support for this study came from the US Department of Agriculture through the Oklahoma Department of Human Services through a Supplemental Nutrition Assistance Program, Nutrition Education Grant (Robert John, PI). We would like to Meredith S. Scott, M.S., Project Coordinator for ONIE, for her contributions to the design and execution of the intervention. This research was a component of a $1 \%$ low-fat milk intervention that received the National Social Marketing Centre (Great Britain) Award for Excellence in Social Marketing announced at the University of South Florida's 24th Social Marketing Conference, 2016. The funding agencies had no role in the design, analysis, or writing of this article. The interpretations expressed here are the authors and do not reflect the views of the funding agencies.

Author Contributions: All authors listed contributed substantially to this project and manuscript. R.J., K.J.F., and D.S.K. conceived and designed the study; K.J.F. assembled the data; D.S.K. performed the quantitative data analysis; R.J., D.S.K., K.J.F., J.O. and K.H. analyzed the qualitative data and contributed to the interpretation; R.J., K.J.F., and D.S.K. made substantial contributions to writing the manuscript; and all named authors have reviewed the manuscript.

Conflicts of Interest: The authors declare no conflict of interest. The funding agencies had no role in the design of the study, in the collection, analysis, or interpretation of data, or the writing of the manuscript.

\section{References}

1. US Department of Agriculture and the US Department of Health and Human Services. Scientific Report of the 2015 Dietary Guidelines Advisory Committee; US Human Nutrition Information Service: Washington, DC, USA, 2015.

2. US Department of Agriculture and the US Department of Health and Human Services. Nutrition and Your Health: Dietary Guidelines for Americans, 3rd ed.; US Human Nutrition Information Service: Washington, DC, USA, 1990. Available online: https:/ / health.gov/dietaryguidelines/1990.asp (accessed on 12 April 2017).

3. US Department of Health and Human Services and US Department of Agriculture. 2015-2020 Dietary Guidelines for Americans, 8th ed.; Department of Health and Human Services: Washington, DC, USA, 2015. Available online: http:/ / health.gov / dietaryguidelines/2015/guidelines/ (accessed on 1 February 2016). 
4. US Department of Agriculture Services and US Department of Agriculture. Dietary Guidelines for Americans, 7th ed.; Government Printing Office: Washington, DC, USA, 2010. Available online: https://health.gov/ dietaryguidelines/dga2010/dietaryguidelines2010.pdf (accessed on 20 November 2011).

5. US Department of Agriculture Services and US Department of Agriculture. Dietary Guidelines for Americans, 6th ed.; Government Printing Office: Washington, DC, USA, 2005. Available online: https://health.gov/ dietaryguidelines/dga2005/document/ (accessed on 12 April 2017).

6. US Department of Agriculture and the US Department of Health and Human Services. Nutrition and Your Health: Dietary Guidelines for Americans, 5th ed.; Government Printing Office: Washington, DC, USA, 2000. Available online: https:/ /health.gov/dietaryguidelines/2000.asp (accessed on 12 April 2017).

7. US Department of Agriculture and the US Department of Health and Human Services. Nutrition and Your Health: Dietary Guidelines for Americans, 4th ed.; Government Printing Office: Washington, DC, USA, 1995. Available online: https:/ / health.gov/dietaryguidelines/1995.asp (accessed on 12 April 2017).

8. US Department of Agriculture. In Fluid milk sales by product (Annual) [Data file]; 2012. Available online: http:/ / www.ers.usda.gov / data-products/dairy-data.aspx (accessed on 5 May 2017).

9. Rehm, C.D.; Drewnowski, A.; Monsivais, P. Potential Population-level Nutritional Impact of Replacing Whole and Reduced-fat Milk with Low-Fat and Skim Milk among US Children Aged 2-19 years. J. Nutr. Educ. Behav. 2015, 47, 61-68. [CrossRef] [PubMed]

10. US Department of Agriculture Food and Nutrition Service. (2015) Supplemental Nutrition Assistance Program State Activity Report: Fiscal Year; 2014. Available online: www.fns.usda.gov/sites/default/files/ FY14\%20State\%20Activity\%20Report.pdf (accessed on 4 April 2017).

11. Finnell, K.J.; John, R.; Thompson, D.M. 1\% Low-Fat Milk has Perks!: An Evaluation of a Social Marketing Intervention. Prev. Med. Rep. 2017, 5, 144-149. [CrossRef] [PubMed]

12. Finnell, K.J.; John, R. A Social Marketing Approach to 1\% Milk Use: Resonance is the Key. Health Promot. Pract. 2017. [CrossRef] [PubMed]

13. Luntz, F. Words That Work: It is Not What You Say, It is What People Hear; Hyperion: New York, NY, USA, 2007; ISBN-13: 978-1401302597.

14. Finnell, K.J.; John, R. Formative Research to Understand the Psychographics of 1\% Milk Consumption in a Low-Income Audience. Soc. Mark. Q. 2017, 23, 169-184. [CrossRef]

15. Blashfield, R.K. Mixture Model Tests of Cluster Analysis: Accuracy of 4 Agglomerative Hierarchical Methods. Psychol. Bull. 1976, 83, 377-388. [CrossRef]

16. Johnson, S.C. Hierarchical Clustering Schemes. Psychometrika 1967, 32, 241-254. [CrossRef] [PubMed]

17. Kettenring, J.R. The Practice of Cluster Analysis. J. Classif. 2006, 23, 3-30. [CrossRef]

18. Borgen, F.H.; Barnett, D.C. Applying Cluster Analysis in Counseling Psychology Research. J. Couns. Psychol. 1987, 34, 456-468. [CrossRef]

19. Clatworthy, J.; Buick, D.; Hankins, M.; Weinman, J.; Home, R. The Use and Reporting of Cluster Analysis in Health Psychology: A Review. Br. J. Health Psychol. 2005, 10, 329-358. [CrossRef] [PubMed]

20. Punj, G.; Stewart, D.W. Cluster Analysis in Marketing Research: Review and Suggestions for Application. J. Mark. Res. 1983, 20, 134-148. [CrossRef]

21. Dice, L.R. Measures of the Amount of Ecologic Association between Species. Ecology 1945, 26, $297-302$. [CrossRef]

22. Yule, G.U. On the Methods of Measuring Association between Two Attributes. J. R. Stat. Soc. 1912, 75, 79-652. [CrossRef]

23. Kendall, M.G.; Stuart, A. Inference and Relationship. In The Advanced Theory of Statistics; Griffin: London, UK, 1961; Volume 2.

24. U.S. Census Bureau. American Community Survey-1 Year Estimate: Summary File B01003: Total Population: 2014. Available online: https:/ / factfinder.census.gov/ (accessed on 30 June 2017).

25. Thackeray, R.; Neiger, B.L.; Smith, A.K.; Van Wagenen, S.B. Adoption and Use of Social Media among Public Health Departments. BMC Public Health 2012, 12, 242. [CrossRef] [PubMed]

26. Steptoe, A.; Pollard, T.M.; Wardle, J. Development of a Measure of the Motives Underlying the Selection of Food-The Food Choice Questionnaire. Appetite 1995, 25, 267-284. [CrossRef] [PubMed]

27. John, R.; Kerby, D.S.; Landers, P.S. A Market Segmentation Approach to Nutrition Education among Low-Income Individuals. Soc. Mark. Q. 2004, 10, 24-38. [CrossRef] 
28. Wechsler, H.; Wernick, S.M. A Social Marketing Campaign to Promote Low-Fat Milk Consumption in an Inner-City Latino Community. Public Health Rep. 1992, 107, 202-207. [PubMed]

29. Lee, N.R.; Kotler, P.A. Social Marketing: Changing Behaviors for Good, 5th ed.; SAGE Publications: Thousand Oaks, CA, USA, 2015; ISBN-13: 978-1452292144.

30. Leak, T.M.; Benavente, L.; Goodel, L.S.; Lassiter, A.; Jones, L.; Bowen, S. EFNEP Graduates' Perspectives on Social Media to Supplement Nutrition Education: Focus Group Findings from Active Users. J. Nutr. Educ. Behav. 2014, 46, 203-208. [CrossRef] [PubMed]

31. Tobey, L.N.; Manore, M.M. Social Media and Nutrition Education: The Food Hero Experience. J. Nutr. Educ. Behav. 2014, 46, 128-133. [CrossRef] [PubMed]

32. Seymour, B.; Getman, R.; Saraf, A.; Zhang, L.H.; Kalenderian, E. When Advocacy Obscures Accuracy Online: Digital Pandemics of Public Health Misinformation through an Antifluoride Case Study. Am. J. Public Health 2015, 105, 517-523. [CrossRef] [PubMed]

33. Dunn, A.G.; Leask, J.; Zhou, X.J.; Mandl, K.D.; Coiera, E. Associations between Exposure to and Expression of Negative Opinions about Human Papillomavirus Vaccines on Social Media: An Observational Study. J. Med. Internet Res. 2015, 17, 10. [CrossRef] [PubMed]

34. Freire, P. Pedagogy of the Oppressed, 1st ed.; The Seabury Press: New York, NY, USA, 1970; ISBN-13: 978-0826412768.

(C) 2017 by the authors. Licensee MDPI, Basel, Switzerland. This article is an open access article distributed under the terms and conditions of the Creative Commons Attribution (CC BY) license (http:/ / creativecommons.org/licenses/by/4.0/). 